\title{
Knowledge of Adolescents Regarding HIV/AIDS
}

\author{
Ms. Neema ${ }^{1}$, Ms. Priyanka Krishali ${ }^{1}$, Ms. Indu ${ }^{1}$, Ms. Selvi ${ }^{1}$, Ms. Radha ${ }^{1}$, Ms. \\ Harpreet $^{1}$, Ms. Jyoti ${ }^{1}$, Ms. Kavita Dhiman ${ }^{1}$, Ms. Astha Sharma ${ }^{1}$, \\ Mrs. Vandana Chauhan ${ }^{2}$ and Mrs. Suman Lata ${ }^{2}$ \\ ${ }^{1}$ (Students, Himalayan College of Nursing, SRHU, Dehradun, UK) \\ ${ }_{2}^{2}$ (Faculty, Himalayan College of Nursing, SRHU, Dehradun, UK)
}

\begin{abstract}
Acquired Immune Deficiency Syndrome (AIDS) is a viral disease caused by Human Immunodeficiency Virus (HIV) which affects the immune system of human body. Now a day it's become a problem of whole world. The aim of this study was to assess the knowledge of adolescents regarding HIV/AIDS. Study was conducted in a randomly selected intermediate school, from the selected school sample were selected by convenient sampling technique. Data was collected by administering tools to the sample. The result of the study shows, most of the participants believed that by physical appearance of a person HIV positive status can be detected, HIV and AIDS are same thing, infected person immediately shows symptoms. Most of them had misconception that HIV can be transmitted by donating blood, touching, kissing and hugging, sharing swimming pool, clothes and using common toilets. Most of the participants had knowledge that HIV infection can be prevented by using condom. The mean knowledge score was 23.61 with 3.52 standard deviation. Finding of the study revealed that $29 \%$ adolescent had good knowledge, $46 \%$ had average knowledge and $25 \%$ had poor knowledge about HIV/AIDS.
\end{abstract}

Keywords: Knowledge, adolescents, HIV, AIDS, informative pamphlet

\section{Introduction}

Acquired Immune Deficiency Syndrome (AIDS) is a viral disease caused by Human Immunodeficiency Virus (HIV) which deteriorate the immunity of an individual, makes a person prone for getting serious infection. At present HIV/AIDS becomes a pandemic disease due to uncertain treatment or prognosis. United Nations Programme on AIDS (UNAIDS) reported that approximately 38 million people are HIV positive in the world. Sexually active people comes under high risk group, these are young adults between the age group of 15-30 years, contains around $25 \%$ of total population of country and causes approximately $31 \%$ of AIDS burden.

Adolescence is a period where a child experiences many changes in his/her body. During this period, process of sexual maturation starts which produces interest in sex but in same side brain is not fully matured enough to make correct decisions and to know consequences of sexual behavior. And in our society parents and teachers hesitate to discuss with children about sexuality and sexual diseases like HIV/AIDS. This attitude of elder's creates confusion among young generation. They tend to seek information from different sources such as peer group, social media and may more, which create myths and misconceptions about puberty, sexual relation, safe sex etc. They may have multiple sexual partners, unprotected sex with high risk group, sharing needles, this behaviour make them vulnerable to have repeated risk of HIV infection.

There are studies which show that people did not have sufficient knowledge about HIV/AIDS, modes of transmission and preventive measures. As HIV mainly affects young people which are the most productive age group, affects the economy and development of country. In India there are around 2.5 billion people are HIV positive cases high economic load on country. A survey shows that Andhra Pradesh, Maharashtra, Tamil Nadu, Karnataka, Manipur and Nagaland are most prevalent states for HIV in India. To make the people safe and well educated, Government of India had started National AIDS Control Programme which gives emphasis on the prevention, care and treatment of HIV/AIDS.

National AIDS control organization (NACO) reported that most of the adults who had been diagnosed HIV positive actually got infection during their adolescence period and diagnosed later due to wide incubation period of HIV. UNAIDS reports that there are some social barriers in prevention and treatment HIV/AIDS, these are: confusion, preconception, and fear related to HIV/AIDS. Due to shame and social stigma people do not want to seeking information about HIV/AIDS. This feeling of shame also discourages people to live with HIV, revealing their positive status to family members, spouse and also limit their readiness to take treatment and follow up. There are studies which show that people do not have sufficient knowledge about HIV/AIDS. The result of a study conducted among adolescent students in Lucknow, shows that the overall knowledge of students about HIV/AIDS was satisfactory but they had poor knowledge about high risk groups and cure of HIV/AIDS 
HIV/AIDS is a disease which can be prevented and nurse's role is very important in prevention because a nurse can educate the people about HIV/AIDS. Health education causes positive impact on people. And if the young generation is fully equipped with adequate knowledge then in future there will be healthy adults. The aim of the present study was to evaluate the knowledge of adolescents about HIV/AIDS so that in future we will have well educated and healthy adults.

\subsection{Research statement}

A study to assess the knowledge of adolescents regarding HIV/AIDS with a view to develop and execute an informative pamphlet in selected school of Dehradun, Uttarakhand"

\subsection{Objectives:}

1. To assess the knowledge of adolescents regarding HIV/AIDS.

2. To find association between knowledge and socio-demographic variables.

\section{Materials And Methods}

A descriptive study was conducted in a randomly selected intermediate school from Doiwala block, Dehradun, from this school total 107 sample were selected by convenient sampling technique who fulfilled inclusion criteria. Tool used for the study were socio-demographic data and structured knowledge questionnaire. After collecting data an information booklet about HIV/AIDS (contain information regarding causative agents of AIDS, methods of transmission, myths and misconceptions, prevention and treatment) was explained and distributed to the participants. Content validity of tools and booklet was established by experts. Data analysis was done according to objectives of the study.

\subsection{Sample characteristics:}

\section{Result and findings}

The data presented in table no.1 shows that most of the adolescents $100(93 \%)$ were between the age group of 15-17 years. Out of 107 sample $70(65 \%)$ were female. Thirty four $(32 \%)$ were from $10^{\text {th }}$ class and 73 $(77 \%)$ were from $12^{\text {th }}$ class, from $12^{\text {th }}$ standard $47(44 \%)$ were science and $26(24 \%)$ were art students.

$(\mathrm{N}=107)$

Table no.1: Frequency and percentage distribution of sample characteristics

\begin{tabular}{|c|c|c|c|}
\hline \multicolumn{2}{|l|}{ Variables } & Frequency (f) & Percentage (\%) \\
\hline Age(in years) & $\begin{array}{l}15-17 \\
18-19\end{array}$ & $\begin{array}{l}100 \\
07\end{array}$ & $\begin{array}{l}93 \% \\
07 \%\end{array}$ \\
\hline Gender & $\begin{array}{l}\text { Male } \\
\text { Female }\end{array}$ & $\begin{array}{l}37 \\
70\end{array}$ & $\begin{array}{l}35 \% \\
\mathbf{6 5 \%}\end{array}$ \\
\hline Class & $\begin{array}{l}10^{\text {th }} \\
12^{\text {th }}(\text { Science }) \\
12^{\text {th }}(\text { Art })\end{array}$ & $\begin{array}{l}34 \\
47 \\
26\end{array}$ & $\begin{array}{l}32 \% \\
\mathbf{4 4 \%} \\
24 \%\end{array}$ \\
\hline Living place & $\begin{array}{l}\text { Rural } \\
\text { Urban }\end{array}$ & $\begin{array}{l}99 \\
08\end{array}$ & $\begin{array}{l}\mathbf{9 3 \%} \\
07 \%\end{array}$ \\
\hline Mothers education & $\begin{array}{l}\text { No formal education } \\
\text { Primary education } \\
\text { Secondary education } \\
\text { Graduation and above }\end{array}$ & $\begin{array}{l}32 \\
28 \\
41 \\
06\end{array}$ & $\begin{array}{l}30 \% \\
26 \% \\
\mathbf{3 8 \%} \\
06 \%\end{array}$ \\
\hline Mother's occupation & $\begin{array}{l}\text { House wife } \\
\text { Private employed } \\
\text { Government employed } \\
\text { Self employed }\end{array}$ & $\begin{array}{l}\mathbf{9 8} \\
03 \\
03 \\
03 \\
\end{array}$ & $\begin{array}{l}\mathbf{9 1 \%} \\
03 \% \\
03 \% \\
03 \% \\
\end{array}$ \\
\hline Father's education & $\begin{array}{l}\text { No formal education } \\
\text { Primary education } \\
\text { secondary education } \\
\text { Graduation and above }\end{array}$ & $\begin{array}{l}16 \\
25 \\
45 \\
21\end{array}$ & $\begin{array}{l}15 \% \\
23 \% \\
\mathbf{4 2 \%} \\
20 \%\end{array}$ \\
\hline Father's occupation & $\begin{array}{l}\text { Private employed } \\
\text { Government employed } \\
\text { Self employed }\end{array}$ & $\begin{array}{l}43 \\
09 \\
\mathbf{5 5}\end{array}$ & $\begin{array}{l}40 \% \\
08 \% \\
\mathbf{5 2 \%}\end{array}$ \\
\hline $\begin{array}{l}\text { Familiar } \\
\text { HIV/AIDS }\end{array}$ & $\begin{array}{l}\text { Yes } \\
\text { No }\end{array}$ & $\begin{array}{l}\mathbf{9 8} \\
09\end{array}$ & $\begin{array}{l}\mathbf{9 2 \%} \\
08 \%\end{array}$ \\
\hline Full form of HIV & $\begin{array}{l}\text { Yes } \\
\text { No }\end{array}$ & $\begin{array}{l}\mathbf{6 1} \\
46\end{array}$ & $\begin{array}{l}\mathbf{5 7 \%} \\
43 \%\end{array}$ \\
\hline Full form of AIDS & $\begin{array}{l}\text { Yes } \\
\text { No }\end{array}$ & $\begin{array}{l}59 \\
48\end{array}$ & $\begin{array}{l}\mathbf{5 5 \%} \\
45 \%\end{array}$ \\
\hline
\end{tabular}

Regarding residential area $99(93 \%)$ were from rural area. The mother of $41(38 \%)$ adolescents had secondary education and 98 mothers $(91 \%)$ were house wife. Most of the father of adolescents $45(42 \%)$ had secondary education and $55(52 \%)$ were self-employed. Majority of adolescents $98(92 \%)$ were familiar with the term HIV/AIDS. Sixty one (57\%) knows the full form of HIV and $59(55 \%)$ know the full from of AIDS. 


\section{Knowledge of general information about HIV/AIDS}

Table no. 2(a):-Frequency and percentage distribution of general information of HIV/AIDS

\begin{tabular}{|l|l|}
\hline ITEMS & N=107) \\
\hline Physical appearance can disclose the HIV status & YES (f and \%) \\
\hline HIV and AIDS both are same & $91(85)$ \\
\hline HIV infected person quickly show symptoms. & $70(65)$ \\
\hline Infected person can live without getting symptoms for 5 or more years & $70(65)$ \\
\hline A woman cannot get HIV if she has physical relation during period. & $60(56)$ \\
\hline Infected women will have infected babies & $45(42)$ \\
\hline HIV infection can be confirmed after one week of sexual relation & $40(37)$ \\
\hline A person with HIV can look and feel healthy & $33(30)$ \\
\hline There is no cure for AIDS & $30(28)$ \\
\hline Bleaching powder can kill HIV & $29(27)$ \\
\hline
\end{tabular}

Data presented in table no.2 (a) shows adolescent's knowledge regarding general information about HIV/AIDS, most of the adolescents $91(85 \%)$ said that physical appearance of a person can disclose HIV infected status, $70(65 \%)$ said that HIV and AIDS are same thing, $70(65 \%)$ said that HIV infected person quickly shows serious signs of infection, $60(56 \%)$ adolescents said that infected person can live without getting symptoms of AIDS for 5 or more years, $45(42 \%)$ said that woman cannot get HIV if she has physical relation during mensturation, 40 (37\%) adolescents said that infected pregnant woman will have infected babies, 33 $(30 \%)$ said that confirmation of HIV can be done after one week of sexual relation, $30(28 \%)$ said that a person with HIV can look and feel healthy, 29 (27\%) said that there is no cure for AIDS, only six (05\%) said that HIV can be killed by bleaching powder.

\section{Knowledge about causes and risk factors of HIV/AIDS}

Data in table no.2 (b) shows the knowledge of adolescents regarding causes and risk factors of HIV/AIDS. Majority (92\%) of adolescents responded yes to statement number $1.95(89 \%)$ adolescents believe that AIDS is transmitted through donating blood, $93(87 \%)$ said that HIV is transferred from mother to baby during pregnancy, while other $93(87 \%)$ said physical relation with infected person could cause HIV. Majority $91(85 \%)$ of adolescent said that HIV could also be transmitted by touching a positive person and by multiple sex partners. ( $81 \%$ ) adolescent had misconception that HIV/AIDS can be transferred by kissing, shaking hands and hugging also by sharing swimming pool or cloths of positive person (82\%), $84(78 \%)$ adolescent said that by using common toilet HIV infection can be transmit. $72 \%$ adolescents had knowledge that HIV can be transmit by coming in contact through vaginal secretion, $(65 \%)$ said that it could be transmit through breastfeeding, (59\%) said that exposure to body fluids mixed with blood of infected person can transmit infection, (57\%) believed that it can be spread by coughing and sneezing, (56\%) said that mosquito bite can be a mode of transmission, (53\%) said that by having physical relation HIV can be transmit. Asking about causative organism of AIDS (52\%) said that HIV is a causative organism.

Table no.2 (b): Frequency and percentage distribution of knowledge about causes and risk factors of HIV/AIDS $(\mathrm{N}=107)$

\begin{tabular}{|l|l|}
\hline \multicolumn{1}{|c|}{ ITEMS } & YES \\
\hline HIV can be transmitted by & \\
\hline Sharing needles for injection & $98(92)$ \\
\hline Donating blood & $95(89)$ \\
\hline Mother to baby during pregnancy & $93(87)$ \\
\hline Physical relation with infected person & $93(87)$ \\
\hline Touching a positive person & $91(85)$ \\
\hline Multiple sexual partners & $91(85)$ \\
\hline Kissing, shaking hands and hugging & $87(81)$ \\
\hline Sharing a swimming pool or clothes with infected person & $87(82)$ \\
\hline Using common toilet & $84(78)$ \\
\hline Contact with vaginal secretion or blood & $78(72)$ \\
\hline Mother to baby through breastfeeding & $70(65)$ \\
\hline Touching body fluid mixed with blood of infected person & $64(59)$ \\
\hline Coughing and sneezing & $61(57)$ \\
\hline Mosquito bite & $60(56)$ \\
\hline Physical relation with someone & $57(53)$ \\
\hline Human Immunodeficiency Virus & $56(52)$ \\
\hline Contact with saliva ,tears ,sweat or urine & $55(51)$ \\
\hline Tattoo & $49(45)$ \\
\hline Sharing a glass of water with HIV positive & $34(31)$ \\
\hline
\end{tabular}


Other $(51 \%)$ said that HIV can be transferred from one person to another by coming in contact with saliva, tears, sweat or urine, $49(45 \%)$ said by getting tattoo and $34(31 \%)$ said by sharing a glass of water with HIV positive person can cause other person to harbor the causative organs.

\section{Knowledge about preventive measures of HIV/AIDS}

Data presented in table no.2(c) shows adolescent's knowledge regarding prevention of HIV/AIDS. Majority of adolescents 85 (79\%) had knowledge that by using female condom and $78(72 \%)$ said that by using a latex or rubber condom HIV can be prevented. $67(62 \%)$ said that proper cleaning of genitalia after physical relation will reduce the chance of getting HIV, $54(51 \%)$ said that if a person eat healthy food chances of getting HIV infection can be reduced. $46 \%$ said that by including vitamins in diet HIV can be prevented and 43 (41\%) said that by getting vaccine against HIV infection can be prevented.

Table no2(c): Frequency and percentage distribution of knowledge about prevention of HIV/AIDS

$(\mathrm{N}=107)$

\begin{tabular}{|l|l|}
\hline \multicolumn{1}{|c|}{ ITEMS } & YES f(\%) \\
\hline HIV can be prevented by following these measures & \\
\hline Use of female condom & $85(79)$ \\
\hline Use of latex or rubber condom & $78(72)$ \\
\hline Proper cleaning of genitalia after physical relation & $67(62)$ \\
\hline Eating healthy foods & $54(51)$ \\
\hline Including vitamins in diet & $50(46)$ \\
\hline Getting vaccine against HIV & $43(41)$ \\
\hline
\end{tabular}

\section{Knowledge about treatment of HIV/AIDS}

Data presented in bar diagram no. 1 depicts adolescent's knowledge regarding treatment of HIV/AIDS, $93(87 \%)$ adolescents believes that HIV can be killed by cleaning the affected area by simple water, $46(42 \%)$ said that a person will not get HIV if she/he is taking antibiotics, $44(41 \%)$ believed that if a person is taking treatment for AIDS, cannot transmit HIV infection. 78 (72\%) participants had knowledge that there are many HIV centers in our state which provide free treatment and $61(47 \%)$ said that there are some drugs which are used to treat AIDS.

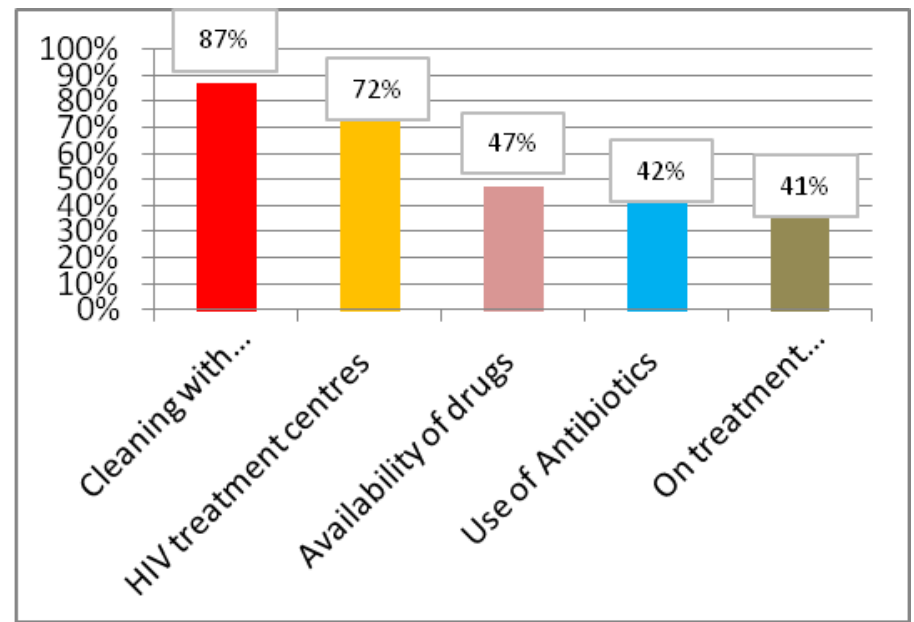

Figure no.1: Bar diagram shows frequency and percentage distribution of treatment about HIV/AIDS

\section{Knowledge score of participants}

Data presented in table no.3 shows that maximum score of structured knowledge questionnaire was 40, obtained range of score was $16-32$, mean was 23.61 with 3.52 standard deviation and median was 24 .

Table No.3: Range, Mean with standard deviation and median of knowledge score

$$
(\mathrm{N}=107)
$$

\begin{tabular}{|l|l|l|l|l|}
\hline \multirow{2}{*}{ Knowledge score } & Max. Score & Obtained range & Mean \pm SD & Median \\
\cline { 2 - 5 } & 40 & $16-32$ & $23.61 \pm 3.52$ & 24 \\
\hline
\end{tabular}

On the basis of obtained scores, the data was divided into three categories good, average and poor. Data presented in table no.4 shows that 31 (29\%) adolescent had good knowledge, 49 (46\%) had average knowledge and 27 (25\%) had poor knowledge about HIV/AIDS. 
Table no.4:- Frequency and percentage distribution of arbitrary score of knowledge

\begin{tabular}{|l|l|l|l|}
\multicolumn{5}{|c}{$(\mathbf{N}=107)$} & Percentage \\
\hline Categories & Range & Frequency & 29 \\
\hline Good & $27-32$ & 31 & 46 \\
\hline Average & $22-26$ & 49 & 25 \\
\hline Poor & $16-21$ & 27 & \\
\hline
\end{tabular}

\section{Association between knowledge score and socio-demographic variables}

There was statistically significant association only between knowledge score and stream of education that is science.

\section{Conclusion}

From the finding of the study, it can be concluded that most of the participants had average knowledge about HIV/AIDS. Study finding also conclude that most of the participants had misconception that by personal appearance of an individual HIV positive status can be detected, HIV and AIDS are same thing, and infected person immediately shows symptoms. Most of the participants believed that HIV can be transmitted by donating blood, touching, kissing, shaking hands, hugging, sharing pools, clothes, using common toilet and HIV can be killed by cleaning an affected area with simple water. Most of the participants had knowledge that HIV can be prevented by using condom and free treatment is provided at HIV center. Only few of them said that there are some drugs which are used to treat AIDS.

\section{References}

[1]. WHO, Topical overview: HIV AIDS 2008 Mar.www.msn.com/discussion/AIDS/WHO

[2]. Park K, preventive and social medicine. $18^{\text {th }}$ ed. Jabalpur. Bhanarsidas Bhanot Publishers ,New Delhi,2005

[3]. Aghanwa HS HIV AIDS and Indian youth(1980-2008) Journal of social aspects of HIV AIDS.2009;Mar; 6(1)

[4]. National AIDS control organisation, department of health and family welfare availablssse at http://www.naco..in/ NACO/Quick_Links/Youth/)

[5]. S. Bhalla, H. Chandwani, D. Singh, C. Somasundaram, S.K. Rasania and S. Singh, Knowledge about HIV/AIDS among senior secondary school students, Health and Population Perspectives and Issues 28 (4): 178-188, 2005 available at http://medind.nic. in/hab/t05/i4/habt05i4p178.pdf

[6]. Gaps Priscilla Idele et.al, Epidemiology of HIV and AIDS Among Adolescents: Current Status, Inequities, and Data, J Acquir Immune Defic Syndr, Volume 66, Supplement 2, July 1, 2014 available at http://data.unicef.org/ corecode/uploads/ document6/uploaded_pdfs/corecode/Epidemiology_of_HIV_and_AIDS_Among_Adolescents_169.pdf

[7]. Lal.S.S, Vasan.R.S, Thankappan.K. gov R; Knowledge and attitude of students in Kerala towards HIV AIDS, sexually transmitted disease and sexuality, National medical journal of India .2000:13 (9) 231-6.

[8]. Priyadharshi Thakur, status of HIV AIDS an executive summary, NACO's HIV estimates .2003 Oct;5(4)

[9]. M. C. Angermeyer. HIV sentinel surveillance and HIV estimation in India - a technical brief, NACO 2007

[10]. Pratibha Gupta Fatima Anjum and Haider Zaidi ;Knowledge about HIV/AIDS among secondary school students and issues;5(2):119-125

[11]. Balk d.Lahiri S .Awareness and knowledge of AIDS among Indian women :Evidence from 13 states.East-west Center Working papers,Popullation Series:83(20096)

[12]. John R. Chapman (2000). "Adolescent sex and mass media: a developmental approach.". Adolescence. Winter (140): 799811. PMID 11214217. 